\title{
EMPLOYEE SHUTTLE BUS ROUTING PROBLEM
}

\author{
*Semih YALÇINDAĞ, Industrial and Systems Engineering Department, Faculty of Engineering, Yeditepe University, \\ Istanbul, Turkey, semih.yalcindag@yeditepe.edu.tr \\ (iDhttps://orcid.org/0000-0002-6544-2657)
}

Received: 20.02.2020, Accepted: 27.05.2020

Research Article

*Corresponding author

DOI: $10.22531 /$ muglajsci.691517

\begin{abstract}
Recently, companies have started to use engineering techniques more than ever due to competitive market conditions, high costs, and limited budgets. To be able to reduce incurred costs and increase profitability, companies deeply analyze all the existing processes carefully. In this work, the Employee Shuttle Bus management process of an international company, which is located in Gebze, is considered, analyzed, and improved through mathematical modeling technique. Unified and Area-Based solution alternatives are developed by extending the mathematical formulation of the widely studied School Bus Routing Problem. Both proposed methods and the current situation of the company have been implemented on GAMS and solved by the CPLEX solver. It has been observed that proposed methods have provided significant cost reduction with respect to the current situation of the company. Among the newly developed methods, the Area-Based method has provided the best cost reduction amounts with less resource usage and shorter tour lengths. Keywords: Vehicle Routing Problem, School Bus Routing Problem, Employee Shuttle Bus Routing Problem
\end{abstract}

\section{ISSÇI SERVIS OTOBÜSÜ ROTALAMA PROBLEMI}

\section{Özet}

Son zamanlarda, şirketler rekabetçi piyasa koşulları, yüksek maliyetler ve sınırlı bütçeler nedeniyle mühendislik tekniklerini her zamankinden daha fazla kullanmaya başladılar. Şirketler, ortaya çıkan maliyetleri azaltabilmek ve karlılığı artırabilmek adına tüm mevcut süreçleri derinlemesine ve detaylı olarak incelemektedirler. Bu çalışmada, Gebze'de bulunan uluslararası bir şirketin çalışanlarının ulaşım araçlarının (işçi servis otobüsü rotalama problemi) yönetim süreci, matematiksel modelleme tekniği ile ele alınmakta, analiz edilmekte ve geliştirilmektedir. Birleştirilmiş ve Alan Bazlı çözüm alternatifleri, çokça çalışllan okul servisi rotalama probleminin matematiksel formülasyonu genişleterek geliştirilmiştir. Hem önerilen yöntemler hem de şirketin mevcut durumu GAMS üzerinde uygulanmış ve CPLEX çözücüsü kullanılarak çözülmüştür. Önerilen her iki yöntemin de şirketin mevcut durumuna göre maliyette önemli bir azalma sağladığı görülmüştür. Yeni geliştirilen yöntemler arasında, Alan Bazlı yöntem daha az kaynak kullanımı ve daha kısa tur uzunlukları ile en iyi maliyet azalımını sağlamıştır.

Anahtar Kelimeler: Araç Rotalama Problemi, Okul Servisi Rotalama Problemi, İşçi Servis Otobüsü Rotalama Problemi Cite

Yalçındağ, S., (2020). “Employee shuttle bus routing problem”, Mugla Journal of Science and Technology, 6(1), 105-111.

\section{Introduction}

Increasing costs, limited budgets, and competitive market conditions are forcing companies to take precautions and to use engineering techniques/methods while planning every single process available within their organizations. To this end, recently, Operations Research (OR) methods are widely considered and applied by several companies to improve efficiency, increase employees' and customers' satisfaction levels, and to maximize profit. Among the available processes, Employee Shuttle Bus (ESB) management is considered to be a complicated and expensive process since the company has to focus not only on its incentives but also the motivations of the employees. This problem is mainly observed once the companies are located in counties/cities with limited public transportation alternatives or once they are not closely located to the city centers.

In this study, we are considering the ESB management problem of an international company having more than 400 employees and located in Gebze, which is almost 50 $\mathrm{km}$ far away from Istanbul and $55 \mathrm{~km}$ far away from Izmit city centers. Thus, this company has been providing the shuttle bus service to its employees (free of charge) to carry them between their homes and the facility as fast as possible with the least effort and cost. However, they have not considered any OR technique to better manage this problem. Due to this fact, in this study, we propose a new mathematical model-oriented 
solution alternative based on the Vehicle Routing Problem (VRP) to better optimize the EBS problem of this company.

VRP is a combinatorial optimization problem that is used to determine a set of routes for a set of vehicles in order to visit a given number of locations. In the general case, each vehicle starts and returns to a depot/facility center such that all the remaining locations are visited exactly once subject to capacity limits and the total cost (i.e., time, distance, money) of visiting all the locations is minimized. The VRP (also known as VRP with Capacity Restrictions (CVRP)) is considered as the generalized version of the Traveling Salesman Problem (TSP), which was first studied by Dantzig et al. [1] in the literature. Rather than considering several vehicles, in TSP, only one vehicle is used without explicitly handling the capacity requirements. In the VRP literature, in addition to the CVRP, there are also other variants such as VRP with Multiple Depots, Open VRP (OVRP), VRP with Distance Constraints (DCVRP), VRP with Time Windows (VRPTW), etc. [2].

In our context, since vehicles that are used to transport employees start from their homes, visit each pick-up locations and move to the facility (depot) in the mornings or do the reverse route in the evenings, another variant of VRP is used for the EBS problem which is known as the School Bus Routing Problem (SBRP) [3, 4]. The proposed mathematical model is integrated and solved by GAMS via CPLEX solver. Since the coverage area of shuttle buses is vast (European Side- Asian Side of Istanbul, Gebze, and İzmit), it might not be possible to find solutions effectively and efficiently with a single model for a single big region (Unified Solution). To this end, we also decomposed the considered territory into sub-areas (regions) and solved the proposed mathematical model for each of the areas independently to increase the effectiveness and efficiency (Area Based Solution). To validate and compare the outcomes of the proposed approaches (both unified and area-based models and solutions), the existing situation (solution) of the company is used. The results show the importance of using an optimization technique while dealing with the EBS process. Both unified and area-based alternatives are successful in decreasing the cost associated with the EBS problem. Among the alternatives, the area-based method performs the best with more than \%23 decrease in the daily total cost with respect to the current practice.

The remainder of this paper is organized as follows. In Section 2, the proposed EBS model is presented. In Section 3, solution alternatives and the data given by the company are discussed. The results are shown in Section 4 . Then the concluding remarks are presented in Section 5 .

\section{Employee Shuttle Bus Routing Problem}

As described previously, the Employee Shuttle Bus Management or Routing (EBSR) problem can be considered under the SBRP setting. In the literature, SBRP has been categorized under different sub-groups depending on the considered problem: bus stop selection, bus route generation, and bus route scheduling, etc. Among these problems, bus stop selection problem $[5,6,7]$ identifies a bus stop location for each student, bus route generation problem $[8,9,10$, $11,12]$ determines the visiting sequences of predetermined bus stops, and bus route scheduling problem [13, 14] includes a time dimension to determine exact loading time of the students. The main focus of this work will be on the route generation part since the company has already fixed the possible pickup locations (bus stops), and the time of loading at each stop is not their primary focus, which is post adjustable. Moreover, in the literature, SBRP has been further classified based on the considered number of schools (single or multiple), fleet mix (homogenous or heterogeneous), objectives (number of buses used, total travel time/distance, total student riding time/distance, total cost, etc.) and the constraints (bus capacity, maximum distance, maximum riding time, maximum stops per route, etc.).

The proposed model is developed to construct vehicle routes starting from the location of the company, then visiting all the delivery/pick-up locations and ending at the homes of the drivers (afternoon routes for returning home) or vise-versa. At this point, even a single index value (i.e., 0) is used for the depot node, the vehicle does not go back to the starting depot as indicated above. Instead of using different indexes for the starting and ending depots, we use the same index but consider different coordinates while calculating the Euclidian distances from and to the depot node. In the case of starting the routes from the location of the company, all the distances from depot to any pick-up location is the same for all vehicles. However, at the end of the tour, distances from any pick-up location to depot differs for each vehicle as each vehicle has different ending points. It is also important to note that as detailed below, since the considered network assumed to have symmetric distances, vehicles follow the same routes both in the morning (while going to work) and in the afternoon (while returning home). Hence, all the traveling costs are multiplied by 2 to obtain the total daily round (morning and afternoon routes) routing costs.

\section{Sets:}

$V$ : Set of locations $(0, \ldots, \mathrm{N})$

K: Set of vehicles $(0, \ldots, B)$

\section{Parameters:}

$c_{i j k}$ : Distance between location $i$ and $j$ with vehicle $k$ 
$F_{k}$ : Daily leasing (fixed) cost of vehicle $k$

$W_{j}$ : Daily cost required to pay to un-served employees living around location $j$

$d_{j}$ : Total number of employees living around location $j$

$Q_{k}$ : Capacity of vehicle $k$

Mxt: Maximum extra distance that an employee can travel

$\alpha$ : Penalty cost long travels

$N$ : Total number of locations

$B$ : Total number of vehicles

$T$ : Fuel cost

\section{Decision Variables:}

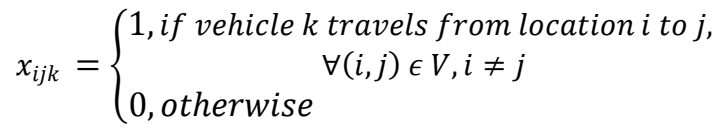

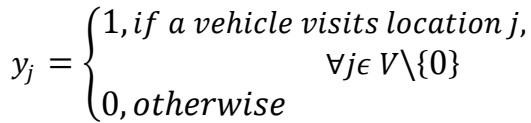

ex $x_{j}=$ Extra distance travelled by the employees living around location $j, \forall j \in V \backslash\{0\}$

$$
\begin{gathered}
\min \sum_{i \in V} \sum_{j \in V} \sum_{k \in K} 2 T c_{i j k} x_{i j k}+\sum_{j \in V} \sum_{k \in K} F_{k} x_{0 j k} \\
+\sum_{j \in V} 2 W_{j} d_{j} y_{j}+\sum_{j \in V} 2 \alpha d_{j} e x_{j} \\
\sum_{k \in K} \sum_{i \in V} x_{i j k} \leq 1 \quad \forall j \in V \backslash\{0\} \\
\sum_{k \in K} \sum_{j \in V} x_{i j k} \leq 1 \quad \forall i \in V \backslash\{0\} \\
\sum_{i \in V \backslash\{0\}} x_{i 0 k} \leq 1 \quad \forall k \in K \\
\sum_{j \in V \backslash\{0\}} x_{0 j k} \leq 1 \quad \forall k \in K \\
\sum_{k \in K} \sum_{j \in V \backslash\{0\}} x_{0 j k} \leq B \\
u_{0}=0
\end{gathered}
$$

$$
\begin{gathered}
u_{i}-u_{j}+M x_{i j k} \leq M-c_{i j k} \forall i \in V, \forall j \in V \backslash\{0\}, \\
\forall k \in K \\
\sum_{i \in V} \sum_{\epsilon \in \backslash\{0\}} x_{i j k} d_{j} \leq Q_{k} \forall k \in K \\
\sum_{i \in V} x_{i p k}=\sum_{j \in V} x_{p j k} \forall p \in V, \forall k \in K \\
y_{j}+\sum_{k \in K} \sum_{i \in V} x_{i j k}=1 \quad \forall j \in V \backslash\{0\} \\
u_{j}-c_{0 j 1}=e x_{j} \forall j \in V \backslash\{0\} \\
e x_{j} \leq M x t \forall j \in V \backslash\{0\}
\end{gathered}
$$

Total daily cost is minimized in the objective function (1), which is composed of daily fuel cost of all vehicles/busses (routing cost), daily leasing cost of all vehicles/busses (fixed cost), daily traveling cost of employees that do not use any bus (individual travel penalty cost), and daily penalty cost of long travel distances of the employees (un-satisfaction cost). As seen, the first two terms are based more on the operational aspects, and the last two ones are based more on employee satisfaction issues. More specifically, in the first term, Euclidian distances are first multiplied by average fuel cost per $\mathrm{km}$ and then by 2 to obtain the round trip fuel cost. At this point, we assume that the distance matrix is symmetric, and vehicles follow the same route both in the morning and in the afternoon. In the second term, heterogeneous daily vehicle costs are multiplied with the corresponding leased vehicles. In the third cost term, firstly $W_{j}$ for each demand point, $j$ is calculated, which is based on the public transportation cost incurred to reach the company (or vice versa) and a penalty factor that depends on the number of transfers required between the public transportation modes/vehicles. Then, $W_{j}$ is multiplied further by two and the number of employees $\left(d_{j}\right)$ that are located around location $\mathrm{j}$ to obtain daily total penalized cost occurred due to not providing any bus service. In the last objective term, daily total penalty cost of extra distances is calculated by taking into account daily extra travel distances $\left(2 * e x_{j}\right)$ between the pick-up/delivery locations and the company (instead of directly going from point $j$ to company), number of employees in each pick-up/delivery location, and the penalty cost per $\mathrm{km}$ $(\alpha)$.

Constraints (2) and (3) ensure that each pick-up location can be visited at most once, which indicates that only one vehicle can stop by each pick-up location. Constraints (4) and (5) state that if a vehicle/bus is used, then it can leave and arrive at the designated depot node at most once. With this constraint, it is 
ensured that if a vehicle is used, then it is not allowed to do several tours between the depot and pick-up locations. Constraint (6) puts an upper bound on the number of vehicles that can leave the depot. In other words, the maximum number of vehicles that can be used is limited. Constraint (7) ensures that all the vehicles start their routes from the depot. Constraints (8) are the sub-tour elimination constraints to prevent vehicles from creating tours that start and end in different locations than depot. Constraints (9) are the capacity constraints to ensure that not more employees than the capacity of the vehicle are assigned. Constraints (10) are the classical flow conservation constraints to ensure that if a vehicle stops by a pick-up location, it continues to its tour afterward. Constraints (11) identify if a bus stops at a pick-up/delivery location or not. $y_{j}$ variables are set equal to 0 for the pick-up/delivery locations having more than three employees. Constraints (12) calculate the extra distances spent by the employees from the location of the company to the designated delivery location with respect to the direct transportation distance between these two locations. Since distances from the location of the company to any pick-up/delivery location is the same for all the vehicles, an arbitrary vehicle index " 1 " is chosen and used to demonstrate the direct distance, $c_{0 j k}$. Finally, in constraints (13), extra distances are bounded with a maximum value, $M x t$, to limit the long travels.

The proposed mathematical model searches for the best leasing solution (including the driver) with less than or equal to $B$ vehicles. However, as the result of the discussion made with the company, it is said that it will never be possible to lease less than a pre-determined number of vehicles according to their previously made agreement with a leasing company (i.e., at least 25 vehicles should be leased). To this end, the following constraint is included in the mathematical model to satisfy this condition where $L B$ is a lower bound value on the number of vehicles to be used.

$$
\sum_{k \in K} \sum_{j \in V \backslash\{0\}} x_{0 j k} \geq L B
$$

\section{Data and Solution Methods}

Most of the data such as the number of employees (448 employees), the number of vehicles (33 vehicles) and their characteristics (i.e., capacities $(9,15,16$ or 27 persons), renting costs, fuel costs, etc.), employees' pickup/delivery locations (134 different locations), and drivers' ending locations have been provided by the company. In the provided data, only the names of the pick-up/delivery locations have been provided (e.g., Göztepe Köprüsü, Kavacık TEM Çıkışı, etc.) instead of the exact coordinates. Hence, we have generated the approximate Cartesian coordinates according to these given pick-up/delivery locations. Then, Euclidean distances $\left(c_{i j k}\right)$ have been calculated where 1 unit Euclidean distance is assumed to correspond to 0.284 $\mathrm{km}$. In particular, since we have considered a selftransportation option for some of the employees, we have obtained the public transportation directions for the pick-up/delivery locations having less than three employees together with the number of transfers required. Following that, self-transportation costs have been calculated by using the actual public transportation tariff. Lastly, maximum allowed distance, i.e., $M x t$, that can be traversed by an employee is set equals to $70 \mathrm{~km}$.

As described before, EBS can be considered as a variant of the route generation problem of the SBRP class, which is known to be an NP-hard problem [7]. To this end, solving the proposed mathematical model of the EBS problem with 134 demand points and up to 33 vehicles might not be easy (i.e., Unified Solution Method). As an alternative, we have divided the service territory into six sub-areas (with close consultation of the company) and solve the proposed model for each area independently with fewer demand points and vehicles (i.e., Area-Based Solution Method). Maps with pick-up/delivery locations of the unified and area-based alternatives are presented in Fig 1 and 2, respectively. All the parametric details for both solution alternatives are given in Table 1.

As it can be seen from Table 1, 3 different $L B$ configurations for the unified approach has been implemented to directly compare it with the real case $(\mathrm{LB}=33)$, to compare it with the Area-Based alternative $(\mathrm{LB}=25)$ and to create a new configuration $(\mathrm{LB}=28) . \angle B$ values of the Area-Based approach has been decided with the company with a total value of 25 . In the AreaBased setting, vehicles are assigned to a single area before solving the mathematical models and are not considered in the solution of the other areas.

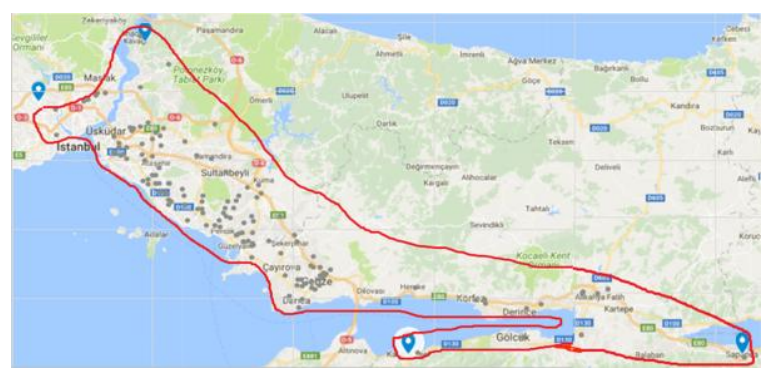

Figure 1. Unified Solution Method

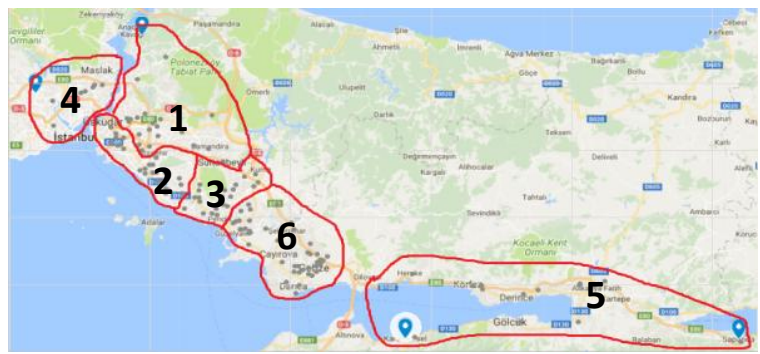

Figure 2. Area-Based Solution Method 
Table 1. Input Parameters.

\begin{tabular}{|c|c|c|c|c|c|c|}
\hline $\begin{array}{l}\text { Solution } \\
\text { Method }\end{array}$ & $\begin{array}{c}\text { Area } \\
\text { ID }\end{array}$ & $N$ & $B$ & $L B$ & $\sum_{j \in V \backslash\{0\}} d_{j}$ & $\sum_{\forall k \in K} Q_{k}$ \\
\hline \multirow{6}{*}{$\begin{array}{l}\text { Area- } \\
\text { Based } \\
\text { Solution }\end{array}$} & A1 & 19 & 5 & 3 & 35 & 74 \\
\hline & A2 & 22 & 6 & 4 & 55 & 97 \\
\hline & A3 & 33 & 6 & 5 & 83 & 97 \\
\hline & $\mathrm{A} 4$ & 7 & 1 & 1 & 10 & 16 \\
\hline & A5 & 14 & 2 & 1 & 30 & 54 \\
\hline & A6 & 39 & 13 & 10 & 201 & 240 \\
\hline $\begin{array}{l}\text { Unified } \\
\text { Solution }\end{array}$ & - & 134 & 33 & $\begin{array}{c}25 \\
- \\
28 \\
- \\
33\end{array}$ & 414 & 578 \\
\hline
\end{tabular}

\section{Results}

All the experiments have been run on a Windows machine equipped with CPU Intel Core i7 at $1.80 \mathrm{GHz}$ and $16 \mathrm{~GB}$ of installed RAM. The mathematical model has been written in GAMS and solved via CPLEX 12.6. An optimality gap of $5 \%$ and a time limit of 8 hours have been imposed.

Two main analyses have been considered in the following part where the first one is based on the comparison of the proposed Unified and Area-Based approaches with respect to the existing situation of the company, and the second one is based on the comparison of the Unified approach against the AreaBased one.

The first analysis simply focuses on the quality of the solutions of the proposed approaches and the existing situation according to the objective function values. The existing situation of the company has also been executed with the use of the mathematical model where $x_{i j k}$ and $y_{j}$ variables have been fixed as parameters according to the assignment and routing information given by the company. Fig. 3 presents all the results according to the details provided in Table 1 (results are presented according to Solution Approach_LB, i.e., Area_Based_25, etc.). The solution of the Unified approach with $L B=25$ is not included due to its large optimality gap. In the figure, the total cost represents the objective function value of each alternative, whereas all the remaining ones show the components of the objective function. Even the objective function value is directly obtained as the output of the mathematical model, the total extra distance component in the figure is shown as the daily total extra distance per employee (excluding $\alpha$ and $d_{j}$ ) to present a better comparison metric. The validation of the proposed optimization approach can be done by comparing the current situation of the company with the Unified Approach with 33 vehicles (Unified_33).

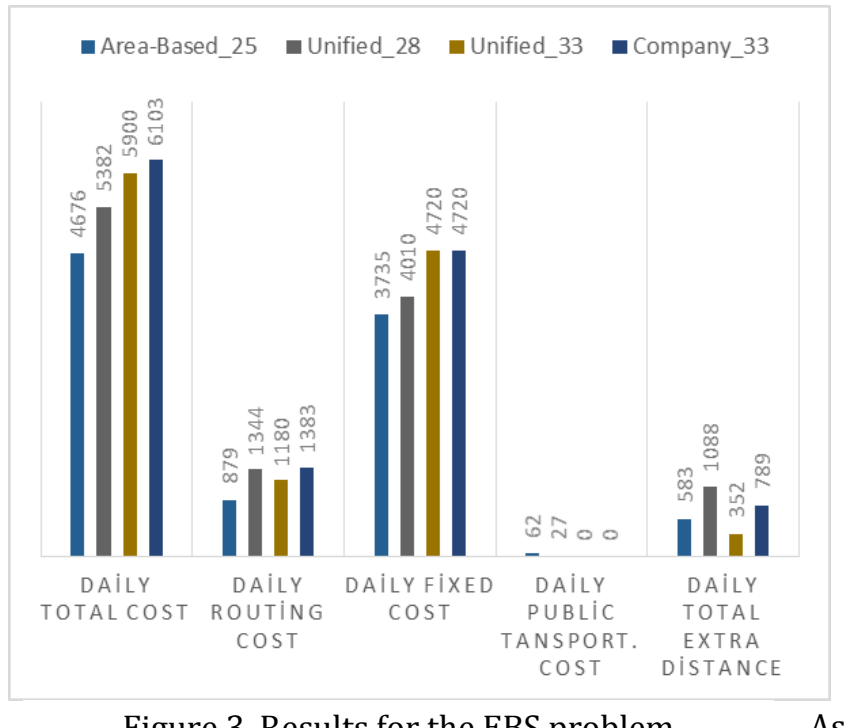

Figure 3. Results for the EBS problem

can be seen from Fig 3., the daily total cost has been decreased by $3.3 \%$. Not observing higher reductions is rather obvious since the fixed cost term in both cases is equal in both alternatives as we are using exactly 33 vehicles. Once we keep the fixed cost term apart, we can observe a $14.7 \%$ reduction in the daily routing cost and a more than $55 \%$ reduction in the daily total extra distance per employee. As a result, we can conclude that the proposed approach is an effective tool to decrease the cost of the company. In particular, it is also presented in the figure that the total cost of the company has been reduced significantly, up to $11.8 \%$ with the Unified Approach and up to $23.4 \%$ with AreaBased Approach. More significant reductions with the Area-Based approach is a consequence of using 26 vehicles instead of 33 vehicles (with $L B=25$ ). It is also important to note that, under the Area-Based setting, only four and under the Unified_28 setting, only two employees are directed to the public transportation option, and all the rest are served by the buses/vehicles of the company.

The second analysis compares the performances of the Unified (U_LB) approach with respect to the Area-Based (AB_LB) one based on the daily total cost value (objective function value), optimality gap (\%gap), solution time (CPU time) and total number assigned vehicles.

Table 2 presents that the Area-Based method (AB_25) provides good quality solutions in shorter solution times. It decreases the daily total cost value by $20 \%$ and 
$13 \%$ wrt. to the U_33 and U_28 alternatives, respectively. Since the total LB value of the Area-Based approach is set equal 25 , we have also tested the Unified approach with the same LB (U_25) value to directly compare both alternatives. As can be seen from the table, it is not possible to compare the quality of the solutions of these methods under the same setting due to the large optimality gap and high solution time of the Unified case. As a result of the analysis presented in Table 2, it can be concluded that the Area-Based approach is a better and more flexible solution approach. In particular, with the inherent flexibility of the Area-Based method, the decision-maker can easily and more quickly re-optimize some areas without touching the others in case of an increase or decrease in the number of employees and/or vehicles. In two of the Unified approach alternatives (the ones that are marked with * sign), only two employees are directed to public transportation, whereas this number increase to 4 in the Area-Based approach. Even this number is a bit higher in the Area-Based approach, it can still be considered as a very small number once we compare it with the total number of employees 448.

Table 2. Comparison Analysis for the Proposed Methods.

\begin{tabular}{cccccc}
\hline $\begin{array}{c}\text { Solution } \\
\text { Method }\end{array}$ & $\begin{array}{c}\text { Area } \\
\text { ID }\end{array}$ & $\begin{array}{c}\text { Total } \\
\text { Cost } \\
\text { (TL) }\end{array}$ & \%Gap & $\begin{array}{c}\text { CPU } \\
\text { Time } \\
\text { (sec) }\end{array}$ & $\begin{array}{c}\text { Total } \\
\text { Number } \\
\text { of } \\
\text { Assigned } \\
\text { Vehicles }\end{array}$ \\
\hline & A1 & 559 & 0.0 & 766.5 & 3 \\
& A2 & 736 & 0.0 & 78.5 & 4 \\
& A3* & 908 & 5.0 & 11598.4 & 5 \\
AB_25 & A4 & 206 & 0.0 & 0.01 & 1 \\
& A5* & 456 & 0.0 & 0.03 & 2 \\
& A6 & 1809 & 5.0 & 7810.5 & 11 \\
\cline { 2 - 6 } & Total & 4674 & - & 20253.9 & 26 \\
\hline U_25* & - & 5382 & 22.0 & 28800 & 27 \\
\hline U_33 & - & 5900 & 10.8 & 28800 & 28 \\
\hline
\end{tabular}

\section{Conclusion}

In real practice, the Employee Shuttle Bus routing problem is generally managed through the intuition and experience of managers, drivers, and other stakeholders of the company. However, executed plans under these circumstances do not usually provide the most costeffective solution to the company.

In this work, to be able to analyze the current situation of the company and to decrease the existing costs of the
EBS process, we have developed Unified and Area-Based solution alternatives by considering and extending the School Bus Routing Problem.

From the analysis, it has been seen that the daily total cost of the company has been decreased up to $23.4 \%$ by the Area-Based approach and up to $11.8 \%$ by the Unified Approach. Hence, it can be concluded the OR based techniques are generally very effective tools not only for scientists but also for decision-makers to improve any considered process or system.

\section{References}

[1] Dantzig G., Fulkerson R. and Johnson S., "Solution of a large-scale traveling salesman problem", Operations Research, 2, pp. 393-410, 1954.

[2] Toth P. and Vigo D., The vehicle routing problem, SIAM Monographs on Discrete Mathematics and Applications, Philadelphia, 2002

[3] Ellegood, W. A., Solomon S., North J. and Campbell J. C., "School bus routing problem: Contemporary trends and research directions", Omega, in Press, 2019.

[4] Park, J. and Kim, B., "The school bus routing problem: a review", Eur J Operat Res, 202 (2), pp. 311-319, 2010.

[5] Galdi, M. and Thebpanya, P.," Optimizing school bus stop placement in Howard county, Maryland: a GISbased heuristic approach", Int J Appl Geospat Res, 7 (1), pp. 30-44, 2016.

[6] Kamali, B. and Mason, S.J., Pohl E.A., "An analysis of special needs student busing", J Public Transp, 16 (1), 2013.

[7] Sarubbi, J.F., Mesquita, C.M., Wanner, E.F., Santos, V.F., Silva, C.M., "A strategy for clustering students minimizing the number of bus stops for solving the school bus routing problem", Network Operations and Management Symposium (NOMS), pp. 11751180, 2016.

[8] Alabas-Uslu, C., "A self-tuning heuristic for a multiobjective vehicle routing problem", J Oper Res Soc, pp. 988-996, 2008.

[9] Kotoula, K.M. Morfoulaki, M., Aifadopoulou, G., and TzenosCalculating P., "The optimal school bus routing and its impact on safety and environment protection", Transp Res Board, 2647 (1), pp 142150, 2017.

[10] Unsal, O. and Yigit, T., "Using the genetic algorithm for the optimization of dynamic school bus routing problem", Broad Res Artif Intell Neurosci, 9 (2), pp. 6-21, 2018.

[11] Uzumer, E. and Eren, T., "Okul Servisi Rotalama Problemi: Bir Uygulama", International Journal of Engineering Research and Development, 4 (2), 2012.

[12] Yigit, T. and Unsal, O., "Using the ant colony algorithm for real-time automatic route of school buses", Int Arab J Inform Technol, 13 (5), pp. 559565, 2016. 
[13] Song, S.M. and Kim T. "Customer-oriented school bus operations for childcare centers in Korea", Comp Indust Eng, 66 (1), pp. 116-124, 2013.
[14] Oluwadare, S.A., Oguntuyi, I.P. and Nwaiwu J.C., "Solving school bus routing problem using genetic algorithm-based model" Int J Intell Syst Appl, 10 (3), pp.

50-58,

2018. 